\title{
Detection of chilli anthracnose caused by Colletotrichum cliviae in India
}

\author{
T. J. Saini ${ }^{1,2}$ - S. G. Gupta ${ }^{3}$ - R. Anandalakshmi ${ }^{1}$
}

Received: 7 April 2017 / Accepted: 19 July 2017 /Published online: 25 July 2017

(C) Australasian Plant Pathology Society Inc. 2017

\begin{abstract}
Chilli fruits with typical anthracnose symptoms of sunken, dark brown necrotic tissue with concentric brown black rings of acervuli around the fruits were observed in the fields in Jalna, Maharashtra, India. Based on morphological and molecular characterization, fungus was identified as Colletotrichum cliviae, which is reported for the first time, causing anthracnose on chilli in India.
\end{abstract}

\section{Keywords Capsicum sp.}

Chilli, Capsicum sp., is one of the most important commercial spice crops and is grown in almost all the states of India. Chilli is an integral ingredient of different cuisines around the world as it adds pungency, taste, flavor, and color to the dishes. India ranks first in dry chilli production in the world with over 1.49 million tonnes produced annually (FAOSTAT 2013).

Anthracnose of chilli fruit, caused by a complex of Colletotrichum species, results in both pre- and post-harvest fruit decay (Liu et al. 2016) with yield losses of up to $50 \%$ (Pakdeevaraporn et al. 2005), which severely affects marketability of the fruits. The species of Colletotrichum, causing chilli anthracnose, reported from India includes Colletotrichum truncatum, C. gloeosporioides, C. dematium,

T. J. Saini

teju.saini@gmail.com

1 Mahyco Research Centre, Dawalwadi, Jalna, Maharashtra 431203, India

2 Department of Biotechnology, Government Institute of Science, Dr. Babasaheb Ambedkar Marathwada University, Aurangabad, Maharashtra 431004, India

3 Government Institute of Forensic Science, Nipatniranjan Nagar, Aurangabad, Maharashtra 431004, India
C. acutatum, C. siamense, C. fructicola (Sharma and Shenoy 2014), C. coccodes and most recently C. karstii (Saini et al. 2016). In August 2016, chilli fruits showing typical anthracnose symptoms of sunken necrotic tissues, with concentric brown black rings of acervuli around the fruits were observed on chilli plants, grown in two different fields in Jalna, Maharashtra (Fig. 1). Around $10 \%$ of the chilli fruits were affected with anthracnose. Fifteen samples of chilli fruits, showing typical anthracnose symptoms, were collected.

Chilli fruits showing anthracnose symptoms were surface sterilised with $1 \% \mathrm{NaOCl}$ for 2 min and then rinsed twice with

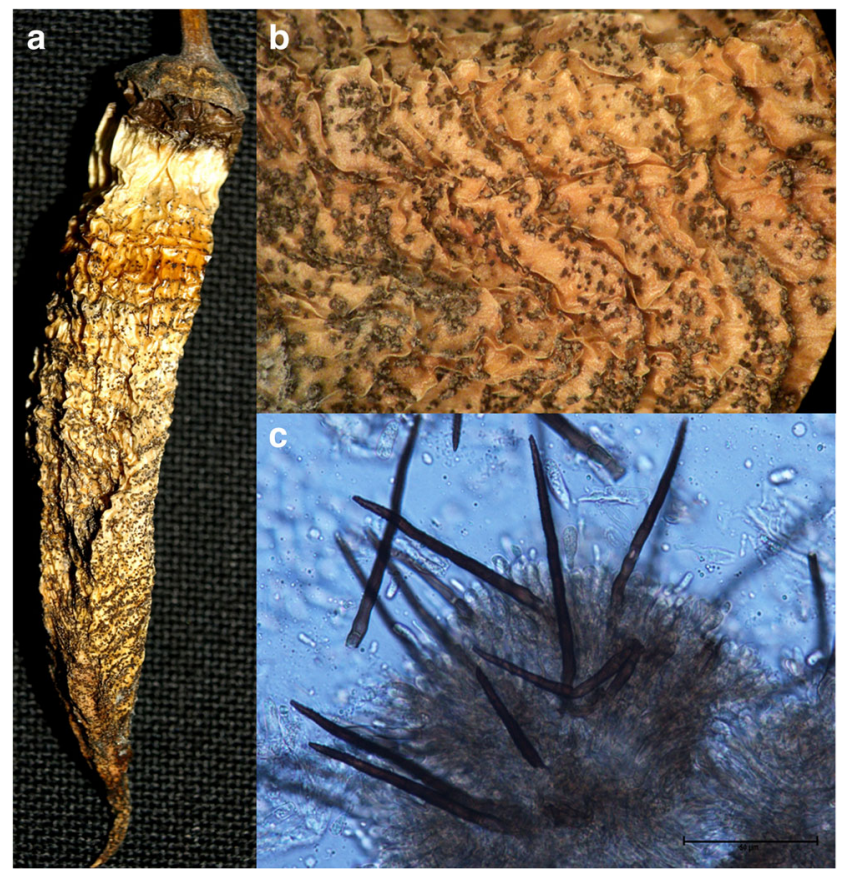

Fig. 1 a anthracnose symptoms of Colletotrichum cliviae on chilli fruit in field; (b-c) acervuli. Bar: $\mathbf{c}=50 \mu \mathrm{m}$ 
Fig. 2 Colletotrichum cliviae on PDA, 10 days post inoculation, (a) from above; (b) from below

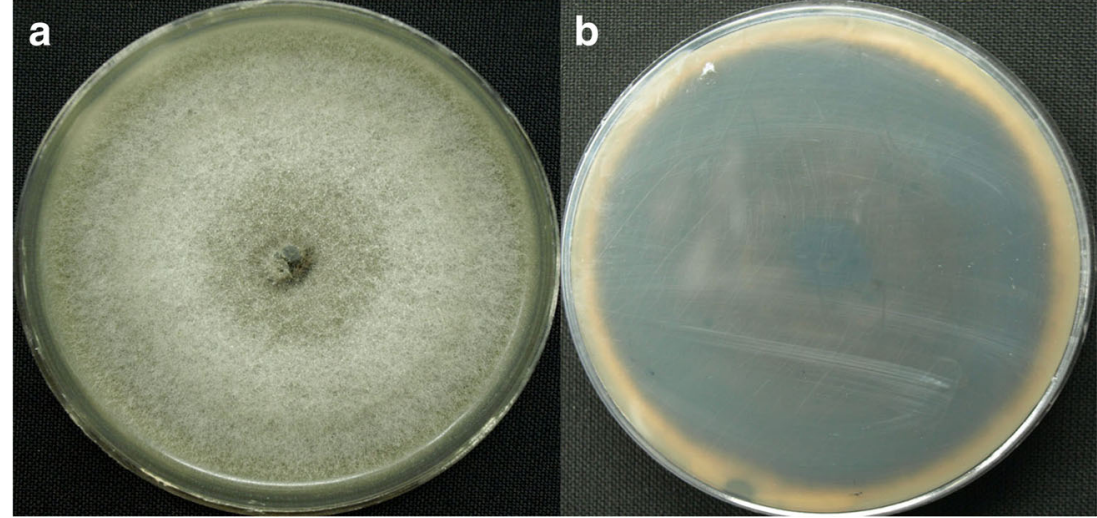

sterile distilled water. Surface sterilised sunken necrotic tissue of chilli was examined under a microscope. Conidia were recovered by dispensing $20 \mu \mathrm{l}$ of distilled water onto visible acervuli (Fig. 1) and their presence was checked under a microscope. Serial dilutions of conidial suspensions were inoculated onto Petri plates containing potato dextrose agar (PDA) amended with $50 \mathrm{mg} / 1$ streptomycin sulphate to get colonies derived from single spores. Plates were then incubated at $28^{\circ} \mathrm{C}$, with $16 / 8 \mathrm{~h}$ light/dark cycle, respectively, for 5 to 7 days and a pure culture of the fungus was obtained by sub-culturing on fresh PDA plates. Initial identification of the fungal isolates was based on morphological characteristics of conidia. Out of 15 chilli fruit samples collected, seven fruit samples had C. truncatum infection, three fruit samples had $C$. siamense infection and five fruit samples were found to be infected with Colletotrichum cliviae. Only identification of C. cliviae isolate is described here. Conidia from all five chilli fruit samples were inoculated on PDA plates to obtain pure cultures. Colony morphology and conidial dimensions of all putative C. cliviae pure culture isolates were identical. Colonies on PDA had white aerial mycelia with no visible conidial mass (Fig. 2). Colour of the colony on the reverse side was dark grey. Mycelial growth rate on the PDA plate at $28^{\circ} \mathrm{C}$, with $16 /$ $8 \mathrm{~h}$ light/dark cycle, was $15 \mathrm{~mm}$ per day. Conidia were single celled, hyaline, thin walled, aseptate and cylindrical with rounded base and apex. Length and width of conidia was
20.4-25.4 × 6.2-7.9 $(\bar{X}=23.1 \pm 1.3 \times 6.9 \pm 0.4 \mu \mathrm{m}$, $n=20$ ) (Fig. 3). Morphological characteristics of the fungal isolates matched with the description of Colletotrichum cliviae (Yang et al. 2009).

PCR amplification of partial $\beta$-tubulin gene using the universal primer pair Bt2a/b (Glass and Donaldson 1995), calmodulin, glyceraldehyde-3-phosphate dehydrogenase, chitin synthase 1, glutamine synthetase and actin gene (Weir et al. 2012) was conducted for molecular characterization of the Colletotrichum isolate. Sequences were deposited in GenBank (Accession Nos. KY 551564, KY 551565 , MF289421, MF289422, MF289423, and MF289424, respectively). Partial $\beta$-tubulin gene and calmodulin gene sequences were used for alignment with published sequences using MEGA version 6.0 (Tamura et al. 2013), and phylogenetic analysis was conducted. Puccinia graminis ( $\beta$-tubulinHM147308; calmodulin-XM003329539) used as an outgroup (Fig. 4). Blast searches in the NCBI database revealed that both $\beta$-tubulin and calmodulin gene sequences had $99 \%$ identity to Colletotrichum cliviae (KJ955361 and KJ954766, respectively). Based on phylogenetic analyses and morphological characteristics, Colletotrichum isolate obtained from chilli fruits was confirmed as $C$. cliviae. The pure culture of C. cliviae has been deposited in the National Fungal Culture Collection of India (NFCCI), Agharkar Research Institute, Pune, India (Accession No.4128).
Fig. 3 Colletotrichum cliviae; (a) conidia; (b) conidial appressoria. Bars: $\mathbf{a}=10 \mu \mathrm{m}$, $\mathbf{b}=50 \mu \mathrm{m}$

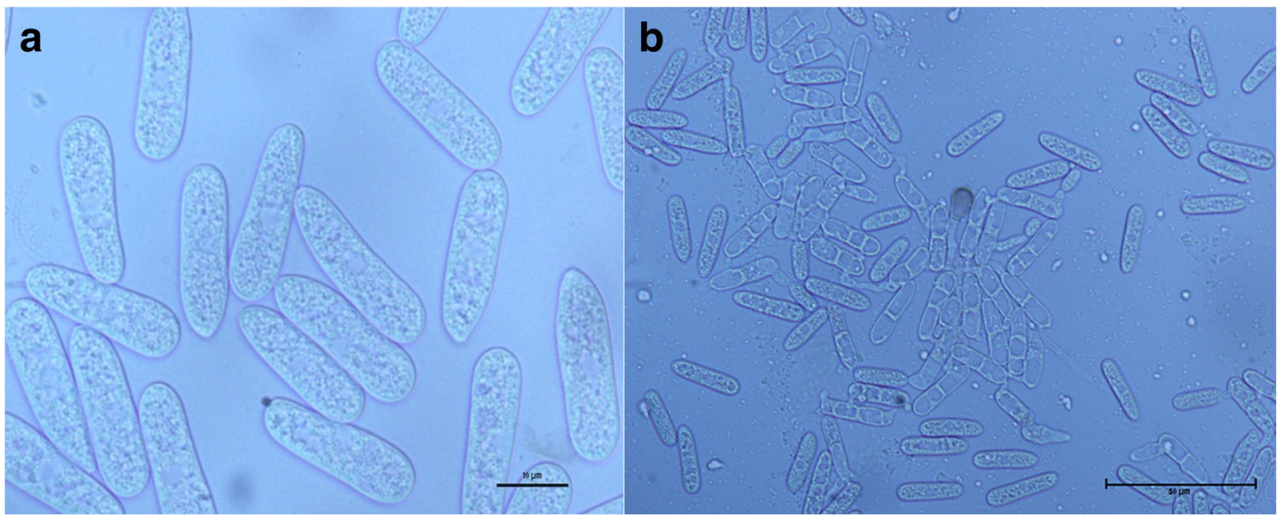




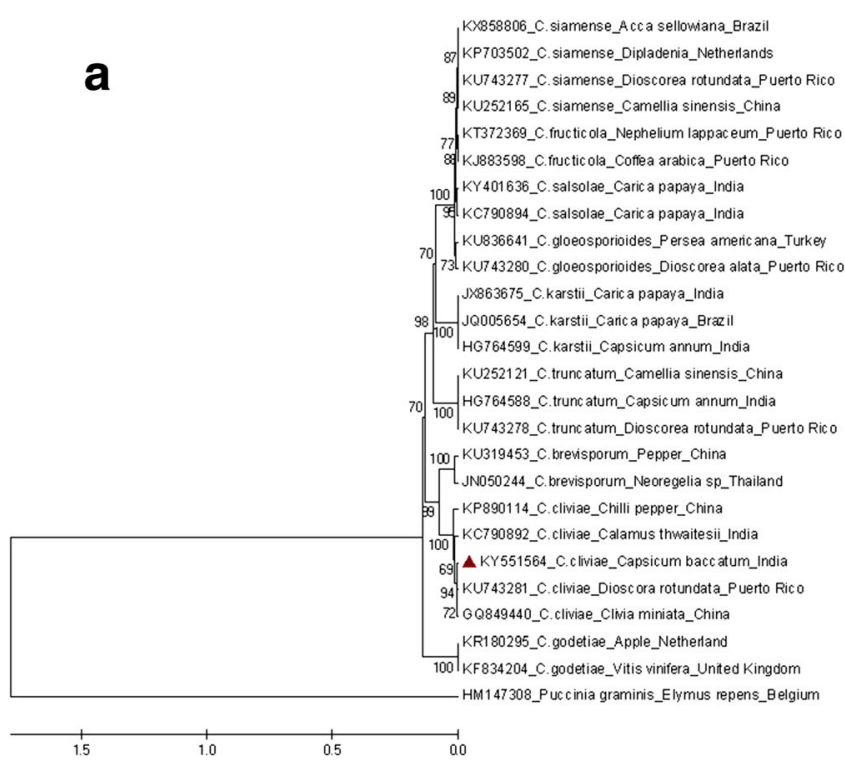

Fig. 4 Phylogenetic tree based on alignment of nucleotide sequences of partial $\beta$-tubulin gene (a) and calmodulin gene (b) from Colletotrichum cliviae identified in this study and reference Colletotrichum species

To confirm pathogenicity, ten chilli fruits of each cultivar (Capsicum annum cv. Phule jyoti, bell pepper- California wonder; Capsicum frutescens cv. PC-1), obtained from plants raised in a green house were first washed with sterile distilled water and then surface sterilised with $70 \%$ ethanol for $30 \mathrm{~s}$. Chilli fruits were pin pricked with a sterile syringe and inoculated with $10 \mu \mathrm{l}$ of a conidial suspension (c. $10^{5}$ conidia/ml) obtained from the PDA culture plate. Five chilli fruits of each cultivar were inoculated with $C$. cliviae spores and remaining five fruits inoculated with sterile water used as controls.

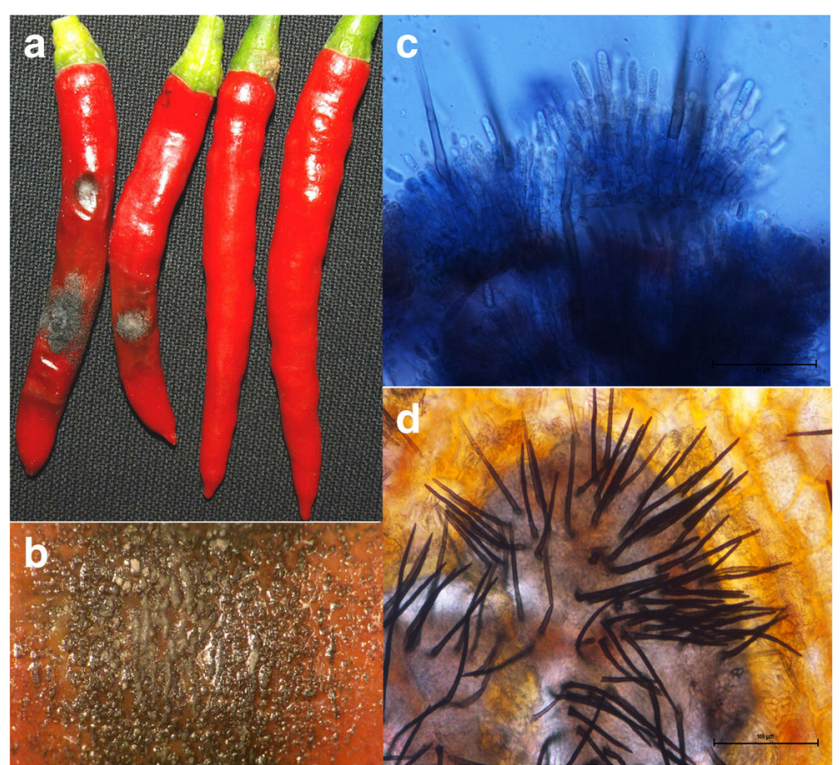

Fig. 5 a Development of anthracnose symptoms following artificial inoculation of Colletotrichum cliviae on chilli fruits cv. Phule jyoti (left) and no symptoms on control fruits (right); (b) anthracnose symptoms on chilli fruit; (c) conidiophores with setae; (d) setae. Bars: c-d $=50 \mu \mathrm{m}$

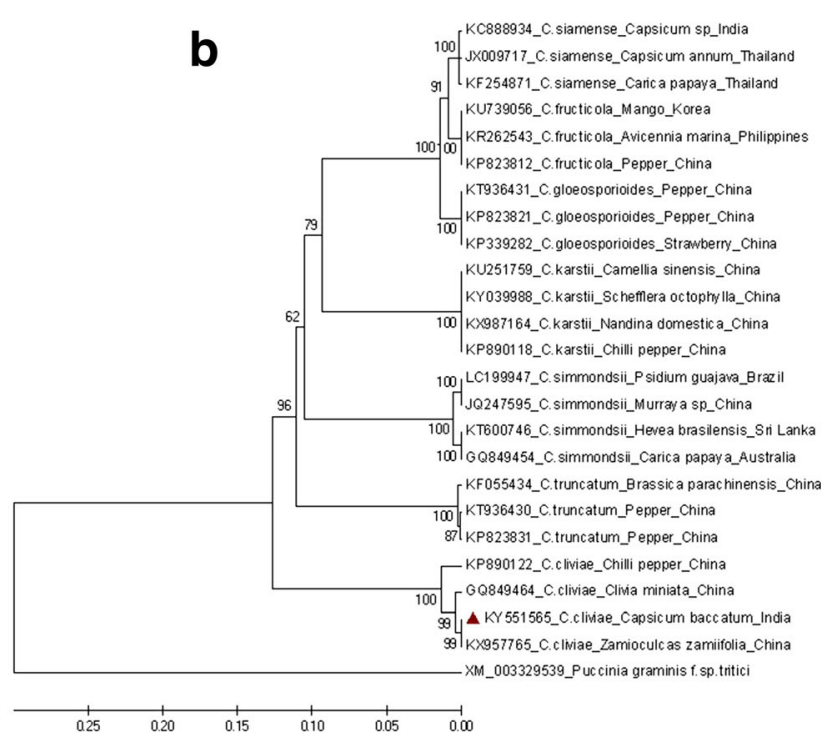

sequences from GenBank. The tree was constructed by the UPGMA method using MEGA version 6.0. The tree is rooted with Puccinia graminis

Inoculated chilli fruits were incubated in a chamber at $28^{\circ} \mathrm{C}$ in dark with $90 \%$ humidity. After 7 days, typical anthracnose symptoms developed on all inoculated chilli fruits of each cultivar (Fig. 5). Pathogenicity experiment repeated three times. Conidia were re-isolated from these diseased inoculated chilli fruits and observed under a microscope. Colony morphology, conidial measurements and sequences were identical to the original inoculated C. cliviae, thereby fulfilling Koch's postulates.

Colletotrichum cliviae has been reported to cause orchid anthracnose in India, (Chowdappa et al. 2014) and chilli anthracnose in China (Diao et al. 2017). To our knowledge, this is the first report of chilli anthracnose caused by C. cliviae in India.

\section{References}

Chowdappa P, Chethana CS, Pant RP, Bridge PD (2014) Multilocus gene phylogeny reveals occurrence of Colletotrichum cymbidiicola and C.cliviae on Orchids in north east India. J Plant Pathol 96(2):327334

Diao YZ, Zhang C, Liu F, Wang WZ, Liu L, Cai L, Liu XL (2017) Colletotrichum species causing anthracnose disease of chili in China. Persoonia 38:20-37. doi:10.3767/003158517X692788

FAOSTAT (2013) FAOSTAT data collection. http://www.fao.org/faostat/ en/\#rankings/countries_by_commodity

Glass NL, Donaldson GC (1995) Development of primer sets designed for use with the PCR to amplify conserved genes from filamentous ascomycetes. Appl Environ Microbiol 61:1323-1330

Liu F, Tang G, Zheng X, Li Y, Sun X, Qi X, Zhou Y, Xu J, Chen H, Chang X, Zhang S, Gong G (2016) Molecular and phenotypic characterization of Colletotrichum species associated with anthracnose disease in peppers from Sichuan Province, China. Sci Rep 6:32761. doi:10.1038/srep32761 
Pakdeevaraporn P, Wasee S, Taylor PWJ, Mongkolporn O (2005) Inheritance of resistance to anthracnose caused by Colletotrichum capsici in Capsicum. Plant Breed 124:206-208. doi:10.1111/j.14390523.2004.01065.x

Saini TJ, Gupta SG, Char BR, Zehr UB, Anandalakshmi R (2016) First report of chilli anthracnose caused by Colletotrichum karstii in India. New Dis Rep 34:6. doi:10.5197/j.2044-0588.2016.034.006

Sharma G, Shenoy BD (2014) Colletotrichum fructicola and C. siamense are involved in chilli anthracnose in India. Arch Phytopathol Plant Protect 47:1179-1194. doi:10.1080/03235408.2013.833749
Tamura K, Stecher G, Peterson D, Filipski A, Kumar S (2013) MEGA6: Molecular Evolutionary Genetics Analysis version 6.0. Mol Biol Evol 30:2725-2729. doi:10.1093/molbev/mst197

Weir BS, Johnston PR, Damm U (2012) The Colletotrichum gloeosporioides species complex. Stud Mycol 73:115-180. doi:10. 3114/sim0011

Yang YL, Liu ZY, Cai L, Hyde KD, Yu ZN, Mckenzie EHC (2009) Colletotrichum anthracnose of Amaryllidaceae. Fungal Divers 39: 123-146 